See discussions, stats, and author profiles for this publication at: https://www.researchgate.net/publication/327222176

\title{
Perceived Quality and Service Experience: Mediating Effects of Positive and Negative Emotions
}

Article in Journal of Hospitality Marketing \& Management · August 2018

DOI: 10.1080/19368623.2018.1517071

CITATIONS

0

2 authors:

Manuel Alector Ribeiro

12. University of Surrey

23 PUBLICATIONS 97 CITATIONS

SEE PROFILE

Some of the authors of this publication are also working on these related projects:

Sustainable Tourism Development in Developing Countries View project

Project Create new project "The Routledge Handbook of Tourism in Asia" View project
READS

63

Girish Prayag

University of Canterbury

82 PUBLICATIONS 1,740 CITATIONS

SEE PROFILE 
This is a pre-publication version of the article, accepted for publication in Journal of Hospitality Marketing and Management. Please cite appropriately as follows:

Ribeiro, M. A., \& Prayag, G. (2018). Perceived Quality and Service Experience: Mediating Effects of Positive and Negative Emotions. Journal of Hospitality Marketing \& Management. doi:10.1080/19368623.2018.1517071.

\title{
Perceived Quality and Service Experience: Mediating Effects of Positive and
}

\author{
Negative Emotions
}

\begin{abstract}
Using the cognition-affect-behavior response system, this study examines the effects of three dimensions of perceived quality (service quality, food quality and restaurant atmospherics) and emotions on overall customer service experience in ethnic restaurants. The study builds on the gap in the literature with respect to the evaluation of perceived quality as a higher-order construct consisting of three dimensions. The baseline and two competing models are proposed and tested on a sample of 665 diners to Brazilian restaurants in the United Kingdom (UK). The findings revealed that all hypothesized relationships were statistically significant, except for the relationship between restaurant atmospherics and negative emotions. Only positive emotions mediated the effect of perceived quality on customer service experience. The findings have significant theoretical and managerial implications for service providers and encouraging diners to experience Brazilian restaurants in the UK.
\end{abstract}

KEYWORDS - Service quality, food quality, atmospherics, emotions, customer experience, ethnic restaurants. 


\section{Introduction}

Consumption is increasingly considered as including a steady flow of fantasies, feelings and fun embraced by what has been termed as the 'experiential view' (Holbrook \& Hirschman, 1982). This experiential view considers consumption as primarily a state of subjective consciousness with a diversity of representative significances and hedonic responses. Accordingly, various environmental and consumer related stimuli are processed by an intervening response system (cognition-affect-behavior), known as the C-A-B model, that generates certain output consequences (Holbrook \& Hirschman, 1982). C-A-B is a process model that explains the way a person and the environment interacts to shape eventual behavioral outcomes (Dweck \& Leggett, 1988). This framework proposes that features of situations activate a set of internal reactions, both cognitive and affective, in influencing behavior either separately or together (Pachankis, 2007). In the hospitality literature, this framework has been applied to understand the motives that elicit skepticism about a hotel's environmental claims, which in turn influence both intention to participate in linen reuse programs and revisit intentions (Rahman, Park \& Chi, 2015). Using the C-A-B model, we argue that service quality (SQ), food quality (FQ) and restaurant atmospherics (RAT) are cognitive evaluations by customers that generate affective responses (Jüttner, Schaffner, Windler, \& Maklan, 2013; Peng, Chen, \& Hung, 2017). In turn, the cognitive and affective (positive and negative emotions) evaluations by consumers generate post-consumption behaviors such as the holistic evaluation of customer service experience (CSE) (see Figure 1a).

FQ and SQ have long been considered as fundamental cognitive aspects of dining experience quality evaluations by customers (Jüttner et al., 2013; Namkung \& Jang, 2007; Prayag, Khoo-Lattimore, \& Sitruk, 2015). Likewise, RAT has emerged as an important cognitive aspect of restaurant quality evaluation by customers (Chen, Peng, \& Hung, 2015; Ha \& Jang, 2010; Peng \& Chen, 2015; Walter \& Edvardsson, 2012). FQ, SQ and RAT are, therefore, well established as the primary cognitive dimensions that customers use to evaluate restaurants (Han \& Hyun, 2017). Accordingly, many studies have evaluated the influence of these cognitive aspects on emotions (Chen et al., 2015; Jang \& Namkung, 2009; Liu and Jang, 2009a; Peng et al., 2017; Prayag et al., 2015). Nonetheless, there are three problems in existing studies.

First, there is no consensus on whether SQ, FQ and RAT (Prayag et al., 2015) are independent dimensions in the evaluation of restaurant quality and the relationship between these 
dimensions and emotions (Jang \& Namkung, 2009; Peng \& Chen, 2015; Prayag et al., 2015). As pointed by Han and Hyun (2017) "there is a dearth of empirical research regarding the investigation of the combined role of physical environment, service and food quality" (p.89). This study suggests that there are potentially inter-relationships between these dimensions and as shown in the study of Prayag et al. (2015). Competing models of the relationships between SQ, FQ and RAT exist (Prayag et al., 2015). Second, existing studies have prioritized satisfaction and behavioral intentions as the most important post-consumption behaviors (Han \& Hyun, 2017; Peng et al., 2017) when evaluating cognitive (SQ, FQ and RAT) and affective (positive and negative emotions) outcomes of the dining experience. This has been to the detriment of other post-consumption behaviors such as CSE that has received much academic attention in the services marketing literature (Jüttner et al., 2013; Klaus \& Maklan, 2012; Lemke, Clark, \& Wilson, 2011; Walter \& Edvardsson, 2012). CSE is “the customer's direct and indirect experience of the service process, the organization, the facilities and how the customer interacts with the firm's representatives and other customers" (Walter, Edvardsson, \& Öström, 2010, p.238). The importance of CSE as an outcome of cognitive and affective evaluations in service environments has been highlighted in several studies (Jüttner et al., 2013; Klaus \& Maklan, 2012; Olsson, Friman, Pareigis, \& Edvardsson, 2012). Third, the three dimensions of SQ, FQ and RAT can represent a higher-order construct of perceived quality (PQ) (Ha \& Jang, 2012; Jang \& Namkung, 2009; Prayag et al., 2015) as suggested in previous studies but rarely tested (see Prayag et al., 2015).

Given the above mentioned issues and knowledge gaps in the existing literature, the purposes of this study is three-fold: 1) we identify the relationships and inter-relationships among the six constructs of FQ, SQ, RAT, positive emotions, negative emotions, and CSE; 2) we propose PQ as a second-order construct consisting of three dimensions (FQ, SQ and RAT) and evaluate competing models of PQ and its relationship with emotions (positive and negative) and CSE; 3) we assess whether the relationship between PQ and CSE is mediated by positive and negative emotions. This study contributes to the hospitality literature by testing alternative models of customer dining experiences that identify the theoretical advantage of one perspective over another (MacCallum \& Austin, 2000). The baseline (Figure 1) and competing models (Figures 1b and 1c) proposed are based on the principle that customers progressively assess consumption experiences in a holistic way (Lin \& Mattila, 2010) and that cognition precedes emotions and behavior (Jang \& Namkung, 2009; Kincaid, Baloglu, Mao, \& Busser, 2010; Lazarus, 1991). Nunkoo, Ramkissoon 
and Gursoy (2013) in their analysis of structural equation modeling (SEM) found that assessments of competing models within tourism and hospitality research are rare. By testing alternative models, we also extend the services marketing literature (Jüttner et al., 2013; Walter \& Edvardsson, 2012) by showing the strongest cognitive and affective antecedents of CSE in ethnic restaurant settings.

\section{Literature Review}

\section{Emotions in Restaurant Settings}

An emotion is a kind of sentiment that can arouse, organize and guide the perceptions, thoughts, and behaviors of people (Izard, 1977). Emotions influence all aspects of consumption from prepurchase decisions to post-consumption behaviors (Prayag, Hosany, Muskat, \& Del Chiappa, 2017). Researchers make a distinction between emotions and consumption emotions. Unlike emotion, consumption emotions are aroused particularly throughout product utilization or consumption experiences and can be considered as affective responses (Havlena \& Holbrook, 1986). Consumption emotions are less intense and more specific due to the consumption contexts they are associated with (Phillips \& Baumgartner, 2002). The valence approach consists of measuring both positive and negative emotions (Laros \& Steenkamp, 2005) and has been extensively used to assess consumers' emotional responses to service experiences (Jang \& Namkung, 2009; Peng et al., 2017). In restaurant settings in particular, some studies focus only on

positive emotions (Prayag et al., 2015; Tsaur, Luoh, \& Syue, 2015), arguing that customers typically avoid expressing negative emotions in such settings (Jang \& Namkung, 2009). Others establish that negative emotions are relevant to ethnic restaurants given the lack of customer familiarity with the cuisine (Peng et al., 2017). There is a lack of agreement on the effect of emotions on post-consumption behaviors, the next section develops the literature supporting the baseline model (Figure 1a).

\section{Food Quality (FQ) and Emotions}

FQ is frequently considered as the most significant component of the dining experience that customers evaluate in restaurant performance assessments (Namkung \& Jang, 2007; Prayag et al., 
2015; Sulek \& Hensley, 2004). Several aspects of FQ are evaluated by the customer such as taste, texture, temperature, portion size (Sulek \& Hensley, 2004), freshness, healthy options, and menu item diversity (Namkung \& Jang, 2007; Peng \& Chen, 2015), among others. Several studies establish the positive influence of FQ on positive emotions (Peng \& Chen, 2015; Peng et al., 2017) while others do not find any significant relationship between the two variables (Chen et al., 2015; Jang \& Namkung, 2009; Tsaur et al., 2015). Likewise, several studies establish that poor quality of food gives rise to strong negative emotions (Chen et al., 2015; Jang \& Namkung, 2009; Peng et al., 2017). Hence, the subsequent two hypotheses are proposed:

$\mathrm{H}_{1}$ : FQ has a positive effect on positive emotions

$\mathrm{H}_{2}$ : FQ has a negative effect on negative emotions

\section{Restaurant Atmospherics (RAT) and Emotions}

Dining environments affect customer emotions and RAT is a substantial part of the dining environment (Jang \& Namkung, 2009; Lui \& Jang, 2009; Peng et al., 2017; Prayag et al., 2015). Previous studies suggest that several RAT dimensions are relevant to customer evaluation of the dining experience including design, ambient and social factors (Ryu \& Jang, 2007). Design factors comprise layout and furniture in the restaurant while ambient factors comprise noise, scent, color and music. Social factors comprise crowding, employee appearance and type of customers (Ryu \& Jang, 2007). Several studies establish the positive effect of RAT on positive emotions (Ha \& Jang, 2012; Peng \& Chen, 2015; Prayag et al., 2015; Tsaur et al., 2015). However, this relationship is not consistent across restaurant types. For example in ethnic restaurants, the relationship between positive perceptions of RAT and positive emotions has not been confirmed (Peng et al., 2017). Similarly, poor perceptions of RAT do not always lead to negative emotions (Chen et al., 2015; Jang \& Namkung, 2009). Nevertheless, some studies establish that poor perceptions of RAT can arouse negative emotions (Peng et al., 2017). Hence, we propose that:

$\mathrm{H}_{3}$ : RAT has a positive influence on positive emotions

$\mathrm{H}_{4}$ : RAT has a negative influence on negative emotions 


\section{Service Quality (SQ) and Emotions}

SQ has been extensively researched in the restaurant industry (Chen et al., 2015; Jang and Namkung, 2009; Peng et al., 2017). SQ is described as the consumer judgment of the global excellence or superiority of the service (Zeithaml, Berry, \& Parasuraman, 1988), measured usually by comparing expectations against perceived performance (Parasuraman, Zeithaml, \& Berry, 1988). Customer perceptions and evaluations of SQ in restaurant settings are highly dependent on the performance of employees during service delivery (Ha \& Jang, 2010). Several studies have assessed the positive effect of SQ on positive emotions (Chen et al., 2015; Peng \& Chen, 2015; Peng et al., 2017; Prayag et al., 2015; Tsaur et al., 2015). Negative perceptions of SQ tend to arouse negative emotions in customers (Chen et al., 2015; Peng et al., 2017), with the exception of the research conducted by Jang and Namkung (2009). Accordingly, we propose that:

$\mathrm{H}_{5}$ : SQ has a positive influence on positive emotions

$\mathrm{H}_{6}$ : SQ has a negative influence on negative emotions

\section{Emotions and Customer Service Experience (CSE)}

Customer service experience (CSE) is a fundamental concept in Vargo and Lusch's (2008) servicedominant (SD) logic. According to Schmitt, Joško-Brakus and Zarantonello (2015), every service exchange leads to a customer experience regardless of its nature and form. As such, customer experience evaluation is holistic in nature and incorporates the customer's cognitive, emotional, and social responses to all interactions with a firm (Gentile, Spiller \& Noci, 2007). This experience is completely personal and denotes consumer participation at different stages in the consumption process (Gentile et al., 2007). Service quality research has primarily focused on assessing cognitive dimensions and quality aspects of both service experiences and critical incidents. There is a necessity to evaluate the service experience beyond purely cognitive assessments (Edvardsson, 2005). Researchers have recently shifted their attention to differences in service experiences leading to two parallel areas of literature emerging, namely peak experiences and a general evaluation of customer experience (Klaus \& Maklan, 2012). This particular study is grounded in the latter with the measurement of CSE being challenging given the associated intricacy with the concept (Palmer, 2010). 
Managing the customer experience is a growing stream of research in the hospitality (Miao \& Mattila, 2013) and marketing literatures (Lemon \& Verhoef, 2016). Previous studies have treated customer experience as a sub-dimension of service quality (DiPietro, Khan, \& Bufquin, 2017) but increasingly the marketing literature recognizes that cognitive, affective and sensorial responses, among others, contribute to holistic evaluations of the service experience by the customer (Lemon \& Verhoef, 2016). CSE as a post-consumption behavior has, therefore, both cognitive and affective dimensions (Olsson et al., 2012; Palmer, 2010) that form the holistic nature of the concept (Helkkula, 2011). The customer experience is determined by a series of touchpoints that constitute the customer journey. Each touchpoint can arouse both cognitive and affective evaluations (Lemon $\&$ Verhoef, 2016). However, studies examining the effect of positive and negative emotions on CSE are scarce. Using qualitative techniques, Jüttner et al. (2013) evaluated episodes of the restaurant service experience by categorizing them into positive and negative emotions. Their result showed that from cognitive evaluations, emotional responses such as pleasure, contentment and surprise were aroused, which in turn impacted perceptions of customer service experience. As such we propose that:

$\mathrm{H}_{7}$ : Positive emotions have a positive effect on CSE

$\mathrm{H}_{8}$ : Negative emotions have a negative effect on CSE

\section{$F Q, S Q, R A T$ and $C S E$}

The next set of hypotheses provides support for the competing model (Figure 1b) by arguing that beyond the indirect effects of cognitive evaluations (FQ, SQ and RAT) on CSE via positive and negative emotions, there are also direct effects. As argued by Walter et al. (2010), customer service experiences are shaped by several issues such as social interactions, the physical environment and the core service. These drivers shape customer experience through cognitions, emotions and behaviors. With a few exceptions (Jüttner et al., 2013; Walter \& Edvardsson, 2012; Walter et al., 2010), the relationships between FQ, SQ, RAT and CSE remain to be evaluated in ethnic restaurant settings. Previous studies are mainly qualitative in nature suggesting that experiences of food and beverage in restaurants settings are drivers of CSE. Specifically, visual presentation of the food, menu aspects and type of food influence such evaluations (Walter et al., 2010). In other research conducted by Jüttner et al. (2013), results showed that freshness and food quality were the main cognitive drivers of CSE evaluations in restaurants. Accordingly, we propose that: 


\section{$\mathrm{H}_{9}$ : FQ has a direct influence on CSE}

The physical environment is an important tangible resource that customers draw upon to form views about the intangible services they are about to experience (Edvardsson et al., 2010; Walter and Edvardsson, 2012). In meal experiences at restaurants, Gustafsson, Öström, Johansson, \& Mossberg (2006) argue that the physical environment is a significant aspect of the holistic assessment of the service experience. Walter and Edvardsson (2012) in qualitative interviews with customers found that aspects of the physical environment that drive CSE in restaurants included, interior elements of the physical environment (e.g., furniture, decoration, the room, seating, lighting, music and color) as well as exterior elements (e.g., building, façade, view and landscape). Similar factors were also found to influence favorable and unfavorable evaluations of CSE in restaurant settings (Walter et al., 2010). In the restaurant environment, Jüttner et al. (2013) found that ambiance was the dominant stimuli that influences CSE. As such it can be argued that:

\section{$\mathrm{H}_{10}$ : RAT has a direct influence on CSE}

Social interactions in restaurants as exemplified by guest-employee interactions, guest overall perceptions of service quality, complaint and recovery, and guest-guest interactions have an influence on CSE (Ali, Amin, \& Cobanoglu, 2015; Walter et al., 2010). Customers who perceived that employees were welcoming, service focused, and made them feel valued, were more likely to evaluate CSE favorably (Walter et al., 2010). Customer perceptions of efficient service delivery, pleasant service, personalized attention, and friendly greeting/departure by employees generate positive assessments of customer experience (Jüttner et al., 2013). As such it can be argued that:

\section{$\mathrm{H}_{11}$ : SQ has a direct influence on CSE}

\section{Perceived Quality (PQ)}

The next set of hypotheses pertains to the second competing model (Figure 1c) proposed in this study. Quality has been defined in different ways. Crosby (1979) describes quality as conformance to requirements. Quality is perceived by consumers (Parasuraman et al., 1988) and often researchers have equated PQ with tangible quality (Kincaid et al., 2010) in the hospitality field. Others have defined PQ as the level of quality of restaurants based on customer perceptions of value (Iglesias \& Guillen, 2004). According to cue utilization theory (Olson \& Jacoby, 1972), 
products and services comprise of intrinsic and extrinsic cues that work as measures of their quality. Because of the intangible environment of services, consumers use extrinsic cues such as physical surroundings to form perceptions of intrinsic cues such as employee performance and food quality (Ha \& Jang, 2012). Also, the overall quality of a restaurant as perceived by consumers encompasses both tangible (i.e., food) and intangible (i.e., interactions with employee) experiences (Ryu \& Han, 2010). Hence, FQ, SQ and RAT can be considered as the essential quality constituents of restaurants (Ha \& Jang, 2012; Han \& Hyun, 2017; Lui \& Jang, 2009b; Ryu \& Han, 2010). Jang and Namkung (2009) suggest that these variables form an overall perceived quality dimension but do not evaluate a higher-order construct reflecting their proposition. The general agreement is that PQ has a tri component structure (Lui \& Jang, 2009a; Ha \& Jang, 2010) but studies have not

evaluated this structure as reflecting a higher-order construct. MacKenzie, Podsakoff, and Jarvis (2005, p.715) note that a higher-order measurement "represents all of the conceptual distinctions that the researcher believes are important, and it provides the most powerful means of testing and evaluating the construct."

Previous studies (Kincaid et al., 2010) have established the positive influence of tangible quality, which reflects the sum of perceptions of factors such as food and service, staff, ambiance and cleanliness, among others, on affect. Also, several studies suggest that PQ is an important predictor of post-consumption behaviors (Ha \& Jang, 2012; Prayag et al., 2015). It is therefore reasonable to propose that:

$\mathrm{H}_{12}$ : $\mathrm{PQ}$ has an influence on positive emotions

$\mathrm{H}_{13}$ : $\mathrm{PQ}$ has an influence on negative emotions

$\mathrm{H}_{14}$ : $\mathrm{PQ}$ has an influence on CSE

\section{Mediating effects}

Jang and Namkung (2009) found that positive emotions partially mediated the effect of SQ and RAT on post-consumption behaviors. Others (e.g., Chen et al., 2015; Jang \& Namkung, 2009) found that the effect of FQ on post-consumption behaviors is fully mediated by positive emotions. Peng et al.'s (2017) results showed that the influence of SQ on post-consumption behaviors is fully mediated by positive and negative emotions. Other studies proposed that negative emotions partially mediate the influence of FQ (Chen et al., 2015; Peng et al., 2017) and RAT (Peng et al., 2017) on post-consumption behaviors. Therefore, the indirect effects of FQ, RAT and SQ on post- 
consumption behaviors via positive and negative emotions are well established but there is no consistency in these effects across studies. Similarly as outlined in $\mathrm{H}_{9}, \mathrm{H}_{10}$, and $\mathrm{H}_{11}$, there are direct effects of these variables on CSE. Hence, it can be argued that better perceptions of RAT create positive emotions that are likely to induce favorable behaviors (Ha \& Jang, 2012). Better perceptions of FQ and SQ induce positive emotions, thereby affecting CSE. Given that negative emotions mediate perceived quality factors such as FQ, RAT, SQ and post-consumption behaviors (Peng et al., 2017), it can be argued that poorer perceptions of cognitive factors would heighten negative emotions, which in turn leading to unfavorable evaluations of CSE. As such, we propose that:

$\mathrm{H}_{15}$ : The relationship between cognitive factors (FQ, RAT and SQ) and CSE is mediated by positive emotions

$\mathrm{H}_{16}$ : The relationship between cognitive factors (FQ, RAT and SQ) and CSE is mediated by negative emotions 
Figure $1(a, b, c)$ - Hypothesized baseline model and competing structural models of customer service experience

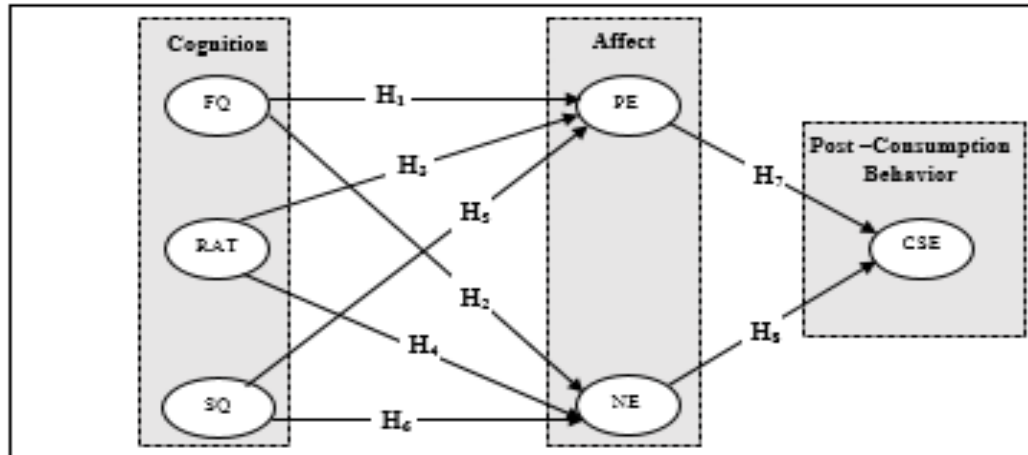

Figure 1(a) - Baseline Model (BM)

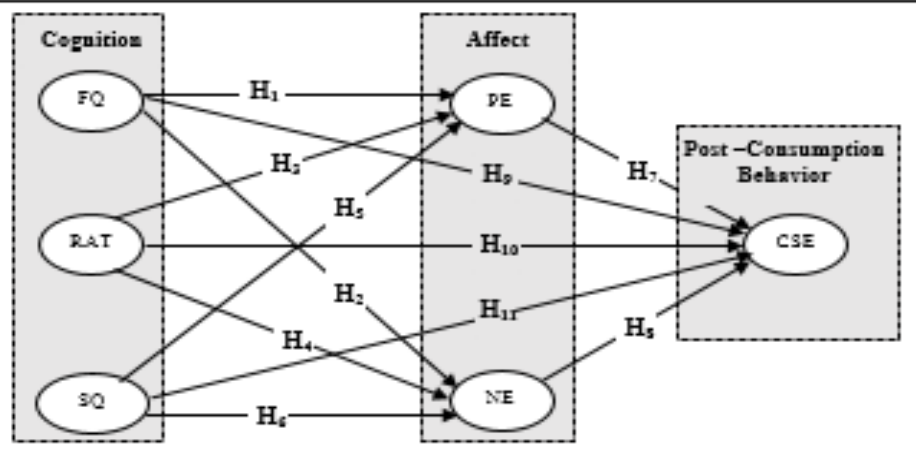

Figure 1(b) - Competing Model $1\left(\mathrm{CM}_{1}\right)$

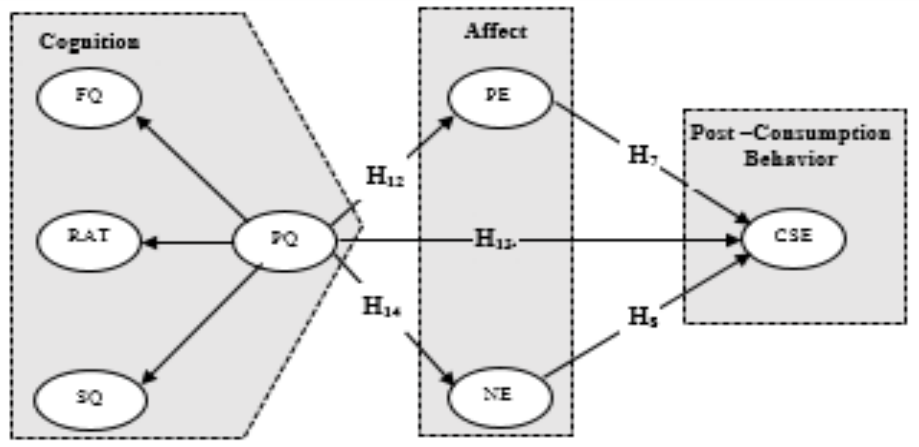

Figure 1(c) - Competing model $2\left(\mathrm{CM}_{2}\right)$

Notes - FQ: Food Quality; RAT: Restaurant Atmospheric; SQ: Service Quality; PE: Positive Emotion; NE: Negative Emotion; CSE: Customer Service Experience; PQ: Perceived Qualit

\section{Methodology}

\section{Measurement instrument}

The measurement instrument for this study comprises multi-item scales validated in previous studies. The items measuring perceived quality of restaurant experience (i.e., food quality, 
restaurant atmospherics and service quality) were adopted from the literature (Chen \& Peng, 2015; Ha \& Jang, 2010; Jang \& Namkung, 2009; Liu \& Jang, 2009b; Namkung \& Jang, 2007; Prayag et al., 2015) and slightly adjusted to capture the intent of the present research. Particularly, FQ, RAT and SQ were measured using 10, 10 and 11 items respectively. Each item was assessed on a fivepoint Likert scale, anchored on 1 (very dissatisfied) to 5 (very satisfied). In addition, items measuring emotions were adapted from several studies (Jang \& Namkung, 2009; Peng \& Chen, 2015; Watson, Clark, \& Tellegen, 1988). These items were classified as positive (excitement, joy, positive surprise, and peacefulness) and negative (anger, disgust, shame and distress) emotions. A five-point Likert scale, anchored on 1 (not at all) to 5 (very much) was used to measure emotions. Five items adapted from Klaus and Maklan (2012) measured the customer service experience and described overall customer evaluation of all the exchanges with the service provider (Edvardsson, 2005). A five point Likert-Scale were used to measure these items, ranging from 1 (Strong disagree) to 5 (Strong agree). The survey also measured sociodemographic variables of the respondents such as gender, age, education and occupation.

\section{Sample, data collection procedures and data analysis}

To analyze the hypothesized model, data were collected in three high end Brazilian ethnic restaurants in the United Kingdom (UK). Brazilian restaurants are proliferating in the UK, mainly after the 2014 FIFA World Cup and 2016 Rio de Janeiro Olympics. An ethnic restaurant segment was chosen because customers are not only interested in food but also the atmospherics as a way of experiencing something new and getting insights into a unique culture (Ha \& Jang, 2010). Data were collected online through an e-mail survey. Every time a customer finished his or her dining experience in one of these restaurants s/he received an e-mail with a link to fill the questionnaire based on his/her experience in the restaurant. The most suitable time to assess emotions is immediately after the experience (King, Meiselman, \& Carr, 2010). Initially, seven Brazilian restaurants brands were identified and three were chosen for data collection because they belong to the same brand and truly represented the uniqueness of Brazilian culture and dining experiences through their food and atmospherics. Also, in these three restaurants the menus are first written in Portuguese, most of the waiting staff can speak this language, and the music played is always Brazilian (Bossa Nova). Furthermore, the food is served in a Brazilian style (rodízio - Brazilian style steakhouse restaurant) which is very different from other ethnic restaurants in the UK. 
Only a customer who made the booking online or by telephone call could participate in the study. Each customer received an individual e-mail invitation with a click-through survey link to fill the questionnaire and a detailed message explaining the objective of the study. In these three restaurants, $80 \%$ of customers who visit the restaurants make their reservation online or by telephone call and only $20 \%$ of customers were walk in. Also, as incentive, respondents were entered into a draw for a gift dinner valued at $£ 100$ to be used in one of the three restaurants. Every week, one respondent in each restaurant was randomly selected by the restaurant management team and offered a gift dinner for two people. Data collection lasted for four weeks in April 2016, with a total of 2982 e-mails sent out to customers, resulting in the completion of 688 surveys. The average time to complete the questionnaire was around eight minutes. Since there were no missing values in the dataset as the forced response option was used, 23 questionnaires were discarded due to the presence of outliers that were identified using the Mahalanobis distance critical value (Tabachnick \& Fidell, 2013). The remaining 665 questionnaires were used for data analysis.

Structural equation modeling (SEM) was used to test the conceptual model and SPSS v24 and AMOS v24 were used to analyze the data. Before testing the proposed model, two preliminary statistical tests were carried out to assess common-method variance (CMV) and normality of the dataset. Consistent with Podsakoff, MacKenzie, Lee, and Podsakoff (2003) recommendations, CMV was verified through Harman's one-factor test. The results revealed that the one-factor failed to explain $50 \%$ of variance, indicating that common-method bias is unlikely to be a pervasive issue in this study. The normality of the data was assessed by examining skewness and kurtosis that influence the analysis of variances and covariances when using SEM. As recommended by West, Finch and Curram (1995), values greater than 3 for skewness and greater than 7 for kurtosis indicate a departure from normality. The results (Table 2), showed that no item presented a skewness or kurtosis higher than the recommended cut-off values, supporting the normality condition for the use of the maximum likelihood estimation in SEM (Kline, 2016).

\section{Results}

\section{Sample Characteristics}

Table 1 presents the sociodemographic characteristics of the survey respondents. Around $54.6 \%$ of respondents were females and $31.3 \%$ were between 26 and 35 years of age, with $26.8 \%$ between 35 to 44 years, $15.6 \%$ under 25 and $8.6 \%$ over the age of 55. Most of the respondents were married 
$(50.0 \%)$ followed by those who were living with a partner $(24.3 \%)$, single $(23.0 \%)$, while the remaining were divorced/separated $(2.4 \%)$ and widowed $(0.2 \%)$. In terms of the highest education level achieved, $49.9 \%$ of the respondents had higher education degrees, followed by $46.2 \%$ of those with secondary education and 3.9\% had completed their primary education. Concerning the respondent occupation, $43 \%$ were professionals, followed by $31.9 \%$ were employed. Of the respondents, $51.7 \%$ reported that they dine out less than once a week but more than once a month and $37 \%$ indicated that they dine out more than once a week. Moreover, $10.7 \%$ of respondents reported that they dine out only on special occasions.

Table 1 - Descriptive summary of sample $(n=665)$

\begin{tabular}{|c|c|c|}
\hline Demographic & $n$ & $\%$ \\
\hline \multicolumn{3}{|l|}{ Gender $(n=665)$} \\
\hline Male & 302 & 45.4 \\
\hline Female & 363 & 54.6 \\
\hline \multicolumn{3}{|l|}{ Age $(n=665$, Mean $=36.4$ years of age $)$} \\
\hline$\leq 25$ & 104 & 15.6 \\
\hline $26-34$ & 208 & 31.3 \\
\hline $35-44$ & 178 & 26.8 \\
\hline $45-54$ & 118 & 17.7 \\
\hline$\geq 55$ & 57 & 8.6 \\
\hline \multicolumn{3}{|l|}{ Marital status } \\
\hline Single & 153 & 23.0 \\
\hline Married & 339 & 51.0 \\
\hline Divorced/Separated & 16 & 2.4 \\
\hline In partnership & 156 & 23.4 \\
\hline Widowed & 1 & 0.2 \\
\hline \multicolumn{3}{|l|}{ Education (median = High/Secondary school) } \\
\hline Primary education & 26 & 3.9 \\
\hline Secondary education & 307 & 46.2 \\
\hline Higher education & 332 & 49.9 \\
\hline \multicolumn{3}{|l|}{ Occupation $(n=463)$} \\
\hline Professional & 286 & 43.0 \\
\hline Student & 21 & 3.2 \\
\hline Self-employed & 34 & 5.1 \\
\hline Administrative & 33 & 5.0 \\
\hline Business owner & 36 & 5.4 \\
\hline Retired & 23 & 3.5 \\
\hline Unemployed & 2 & 0.3 \\
\hline Employed Full-time & 212 & 31.9 \\
\hline Employed part-time & 18 & 2.7 \\
\hline \multicolumn{3}{|l|}{ Dining out experience } \\
\hline Once a week or more & 250 & 37.6 \\
\hline Less than once a week but more than once a month & 344 & 51.7 \\
\hline Only for special occasions & 71 & 10.7 \\
\hline
\end{tabular}




\section{Measurement model}

A two-step approach recommended by Anderson and Gerbing (1988) was followed to analyze the data: (1) Confirmatory Factor Analysis (CFA), and (2) Structural Equation Model (SEM) for hypothesis testing. The results of the preliminary CFA did not fit the data well with $\chi^{2} / d f$ higher than $3\left(\chi^{2}=1877.481, d f=584, \chi^{2} / d f=3.215, p<.001\right)$, and fit indices (i.e., Comparative Fit Index $[\mathrm{CFI}]=0.88$ and Tucker-Lewis index $[\mathrm{TLI}]=0.89)$ less than the cuff-point of $.90(\mathrm{Hu} \&$ Bentler, 1999). The results of Root Mean Square Error of Approximation [RMSEA] $=0.094$ and Standardized Root Mean Square Residual [SRMR] $=0.087$, were above the cut-off point of .08 (Hu \& Bentler, 1999). Inspection of the modification indices and correlation measurement errors resulted in respecification of the measurement model. A careful examination of the results of the model factor structure suggested the deletion of three, four and five items from FQ, RAT, and SQ measures respectively due to correlation measurement errors. As shown in Table 2, the results of the revised measurement model factors for FQ, RAT, and SQ (33 items out of 44) showed good fit with the data. The $\chi^{2} / d f$ was less than $3\left(\chi^{2}=1095.63, d f=401, \chi^{2} / d f=2.73, p<.001\right)$ and fit indices (i.e., CFI = 0.95; TLI = 0.95) were higher than the cuff-point of 90 (Hu \& Bentler, 1999). The results of RMSEA $=0.051$ and $\mathrm{SRMR}=0.037$ were below the cut-off point of $.08(\mathrm{Hu} \&$ Bentler, 1999).

The Composite Reliabilities (CR) exceeded the threshold value of 0.7 (Hair, Black, Babin, \& Anderson, 2014) indicating construct reliability of the measurement scales. As depicted in Table 2 , all items significantly loaded onto their respective constructs $(p<0.001)$. The average variance extracted (AVE) for each construct ranged from 0.81 to 0.94 and these were above the threshold of 0.50 as recommended by Fornell and Larcker (1981). Taken together, these results provide evidence for convergent validity for all constructs in the measurement model (Hair et al., 2014). Discriminant validity was assessed by calculating the square root of the AVE for each specified construct. Table 3 shows the square root of AVE (presented in the diagonal) for each construct was greater than its correlation with all other constructs, providing support of discriminant validity amongst all constructs in the measurement model (Hair et al., 2014). 
Table 2 - Results of the measurement model

\begin{tabular}{|c|c|c|c|c|c|c|}
\hline Constructs and Indicators & Skewness & Kurtosis & Std. $\beta$ & $t$-value & $\mathbf{C R}$ & AVE \\
\hline Food Quality $(\alpha=0.92)$ & & & & & 0.94 & 0.70 \\
\hline Food authenticity & -.603 & 1.108 & .89 & - & & \\
\hline Food presentation & -.596 & .869 & .88 & $46.45^{* * *}$ & & \\
\hline Appropriate food portion & -.548 & 786 & .81 & $29.50^{* * *}$ & & \\
\hline Food taste & -.690 & .917 & .85 & $26.95^{* * *}$ & & \\
\hline Availability of healthy alternatives & -.882 & 2.032 & .76 & $24.23^{* * *}$ & & \\
\hline Freshness of Food & -.709 & 1.303 & .91 & $33.80^{* * *}$ & & \\
\hline Food temperature & -.349 & -.128 & .73 & $22.43^{* * *}$ & & \\
\hline Restaurant Atmospherics $(\alpha=0.91)$ & & & & & 0.91 & 0.62 \\
\hline Authenticity of the atmosphere & -.751 & 1.096 & .74 & - & & \\
\hline Aromas and scents in the establishment & -.813 & 1.496 & .81 & $19.92^{* * *}$ & & \\
\hline Music quality and volume & -.576 & .729 & .85 & $21.17^{* * *}$ & & \\
\hline Comfort of the dining area & -.676 & .748 & .77 & $18.59^{* * *}$ & & \\
\hline Cleanliness of the dining area bathroom & -.612 & .773 & .82 & $20.32^{* * * *}$ & & \\
\hline Pleasant décor & -.459 & .513 & .73 & $18.27^{* * *}$ & & \\
\hline Service Quality ( $\alpha=0.94$ ) & & & & & 0.91 & 0.60 \\
\hline Staff friendliness and helpfulness & -.125 & -.930 & .83 & - & & \\
\hline Staff knowledge of the menu & .096 & -.816 & .85 & $26.07^{* * *}$ & & \\
\hline Staff competency, dependability and consistency & -.098 & -.926 & .80 & $32.46^{* * *}$ & & \\
\hline Level of personalization of the service & .297 & -.438 & .79 & $22.27^{* * *}$ & & \\
\hline Feeling special in the eyes of the staff & -.256 & -.711 & .78 & $22.63^{* * *}$ & & \\
\hline General service levels at XYZ restaurant & .042 & -.647 & .71 & $19.18^{* * *}$ & & \\
\hline Safety of the location & .273 & -.446 & .66 & $19.13^{* * *}$ & & \\
\hline Positive Emotion $(\alpha=0.91)$ & & & & & 0.91 & 0.73 \\
\hline Excitement (excited, thrilled, enthusiastic) & -.448 & -.154 & .88 & - & & \\
\hline Positively surprised & -.964 & 1.276 & .89 & $31.28^{* * *}$ & & \\
\hline Peacefulness (comfortable, relaxed, at rest) & -.608 & .234 & .84 & $28.60^{* * *}$ & & \\
\hline Joy (joyful, pleased, romantic, welcoming & -.693 & .509 & .80 & $25.78^{* * *}$ & & \\
\hline Negative Emotion $(\alpha=0.81)$ & & & & & 0.81 & 0.52 \\
\hline Anger (angry, irritated) & -.427 & -.721 & .76 & - & & \\
\hline Disgust (Disgusted, displeased, bad) & .436 & -.410 & .71 & $16.44^{* * *}$ & & \\
\hline Shame (embarrassed, ashamed, humiliated) & .256 & -.826 & .73 & $16.77^{* * * *}$ & & \\
\hline Distress (frustrated, disappointed, upset) & .279 & -.902 & .70 & $16.18^{* * *}$ & & \\
\hline Customer Service Experience $(\alpha=0.85)$ & & & & & 0.81 & 0.58 \\
\hline $\begin{array}{l}\text { I am confident in XYZ's expertise in Brazilian } \\
\text { cuisine/South America }\end{array}$ & -.853 & 2.000 & .79 & - & & \\
\hline The whole dining process at XYZ was easy & -.763 & 2.403 & .79 & $18.40^{* * *}$ & & \\
\hline $\begin{array}{l}\text { XYZ was flexible in dealing with me and looked } \\
\text { out for my dining needs }\end{array}$ & -.666 & .927 & .72 & $19.77^{* * *}$ & & \\
\hline $\begin{array}{l}\text { I prefer XYZ over an alternative restaurant that } \\
\text { provides a similar experience }\end{array}$ & -.859 & 1.736 & 77 & $18.90^{* * *}$ & & \\
\hline
\end{tabular}

Note. ${ }^{* * *} \mathrm{p}<0.001$ level; $\mathrm{CR}=$ composite reliability; AVE $=$ average variance extracted. 
Table 3 - Descriptive statistics, correlations and the square root of AVE

\begin{tabular}{lcccccccc}
\hline & Mean & SD & FQ & RAT & SQ & PE & NE & CSE \\
\hline Food Quality (FQ) & 4.56 & 0.77 & $\mathbf{0 . 8 4}$ & & & & & \\
Restaurant Atmosphere (RAT) & 4.53 & 0.80 & 0.60 & $\mathbf{0 . 7 9}$ & & & & \\
Service Quality (SQ) & 4.67 & 0.74 & 0.40 & 0.60 & $\mathbf{0 . 7 8}$ & & & \\
Positive Emotion (PE) & 4.30 & 0.70 & 0.55 & 0.47 & 0.55 & $\mathbf{0 . 8 5}$ & & \\
Negative Emotion (NE) & 1.18 & 0.75 & 0.30 & 0.21 & 0.41 & 033 & $\mathbf{0 . 7 2}$ & \\
Customer Service Experience (CSE) & 4.65 & 0.73 & 0.61 & 0.75 & 0.47 & 0.54 & 0.33 & $\mathbf{0 . 7 6}$ \\
\hline
\end{tabular}

${ }^{a}$ The bold elements diagonal are the square root of the average variance extracted; interconstruct correlations is shown off-diagonal. All correlations are significant at the $\mathrm{p}<0.001$ level

\section{Baseline model versus competing models}

The hypothesized relationships between PQ and CSE, mediated by emotions (positive and negative) were tested by estimating three SEM models. The first model (Figure 1a) was the baseline model (BM) which does not integrate the direct effects of the three (FQ, RAT and SQ) cognitive components of PQ on CSE. Results indicate an adequate model fit with $\chi^{2}=1379.36, d f=407$, $\chi^{2} / d f=3.38, p<.001, \mathrm{TLI}=0.93, \mathrm{CFI}=0.94, \mathrm{RMSEA}=0.060$ and $\mathrm{SRMR}=0.075$. The results of the structural path coefficients of the BM showed that of the eight hypothesized relationships tested, seven were found to be significant. The two competing models were analyzed separately. In competing model $1\left(\mathrm{CM}_{1}\right)$, all the exogenous variables were correlated (Figure 1b). In competing model $2\left(\mathrm{CM}_{2}\right)$, the structure of PQ was estimated jointly for the three sub-dimensions (FQ, RAT and SQ) summing a second-order factor model with a common underlying latent variable PQ (Figure 1c) where the items were the observed indicators.

$\mathrm{CM}_{1}$ assessed the effects of the three dimensions of FQ, RAT and SQ on emotions and CSE. The model showed a satisfactory fit to the data $\left(\chi^{2}=1143.98, d f=404, \chi^{2} / d f=2.83, p<.001\right.$, $\mathrm{TLI}=0.94, \mathrm{CFI}=0.95, \mathrm{RMSEA}=0.053$ and $\mathrm{SRMR}=0.038) . \mathrm{CM}_{2}$ was assessed using the three dimensions of FQ, RAT and SQ conceptualized as a second-order factor model. This model assessed the effects of the higher-order factor model on emotions (positive and negative) and CSE. The model showed a good fit $\left(\chi^{2}=1211.87, d f=408, \chi^{2} / d f=2.97, p<.001\right.$, TLI $=0.94$, CFI $=$ 0.95, RMSEA $=0.054$ and SRMR $=0.049$ ). As shown in Table 4, both of the competing models showed a good fit. Furthermore, the $\chi^{2}$ difference test showed that both $\mathrm{CM}_{1}\left(\Delta \chi^{2}=235.38, d f=3\right.$, $p<0.001)$ and $\mathrm{CM}_{2}\left(\Delta \chi^{2}=235.38, d f=3, p<0.001\right)$ fitted the data better than the baseline model (BM) (Figure 1a). 
Table 4 - Result for model comparison

\begin{tabular}{|c|c|c|c|c|c|c|c|c|c|c|c|}
\hline Model & $\chi^{2}$ & $d f$ & $\Delta \chi^{2}$ & $\Delta d f$ & p-value & $\begin{array}{c}\text { TL } \\
\text { I }\end{array}$ & CFI & $\begin{array}{c}\text { RMSE } \\
\text { A }\end{array}$ & SRMR & $\overline{\text { AIC }}$ & BCC \\
\hline Baseline & 1379.36 & 407 & Base comparison & - & .000 & .93 & 94 & .060 & .075 & 1557.36 & 1566.38 \\
\hline $\mathbf{C M}_{1}$ & 1143.98 & 404 & 235.38 & 3 & .000 & .94 & .95 & .053 & .038 & 1327.98 & 1337.29 \\
\hline $\mathrm{CM}_{2}$ & 1211.87 & 408 & 167.49 & 1 & .000 & 94 & 95 & .054 & .049 & 1387.87 & 1396.78 \\
\hline
\end{tabular}

Given that the literature offers support for the three additional paths (Jüttner et al., 2013; Walter et al., 2010) included in $\mathrm{CM}_{1}(\mathrm{FQ} \rightarrow \mathrm{CSE}$, RAT $\rightarrow \mathrm{CSE}, \mathrm{SQ} \rightarrow \mathrm{CSE}$ ), these were tested and the results showed a statistically significant influence on CSE, adding $30 \%$ to the variance explained in $\operatorname{CSE}\left(\mathrm{R}^{2} \mathrm{CM} 1=0.68, \mathrm{p}<0.001\right)$. In doing so, we can conclude that $\mathrm{CM}_{1}$ was better than the BM. To explore a more parsimonious model and test whether FQ, RAT and SQ form a secondorder PQ construct that influences both positive and negative emotions and CSE, a similar procedure as before was used to test the model. $\mathrm{CM}_{2}$ explained $99 \%$ of the variance in $\mathrm{CSE}\left(\mathrm{R}^{2} \mathrm{CM} 2\right.$ $=0.99, \mathrm{p}<0.001)$. This finding shows that the higher-order PQ construct has a strong direct influence on CSE and also indirect effects via positive and negative emotions. Finally, to determine which model fitted the data better, we compared $\mathrm{CM}_{1}$ and $\mathrm{CM}_{2}$ using Akaike information criterion (AIC) (Akaike, 1987) and the Browne-Cudeck criterion (BCC) (Browne \& Cudeck, 1989). The results, based on the values of $\mathrm{AIC}$ and $\mathrm{BCC}$ (see Table 5), confirm that $\mathrm{CM}_{1}$ presented a slightly better fit than $\mathrm{CM}_{2}$. Results of the paths relationships for $\mathrm{CM}_{1}$ are shown in Table 5.

Table 5 - Standardized Regression Weights for the Competing Model $\left(M_{1}\right.$ and $\left.M_{2}\right)$

\begin{tabular}{|c|c|c|c|}
\hline Standardized hypothesized relationship & Std. Estimates & t-Value & Supported? \\
\hline H1: Food Quality $\rightarrow$ Positive Emotion & 0.386 & $5.846^{* * *}$ & Yes \\
\hline H2: Food Quality $\rightarrow$ Negative Emotion & -0.168 & $-3.050^{* *}$ & Yes \\
\hline H3: Restaurant Atmospherics $\rightarrow$ Positive Emotion & 0.168 & $3.702^{* * *}$ & Yes \\
\hline H4: Restaurant Atmospherics $\rightarrow$ Negative Emotion & -0.021 & $-0.377^{\mathrm{ns}}$ & No \\
\hline H5: Service Quality $\rightarrow$ Positive Emotion & 0.350 & $9.668^{* * *}$ & Yes \\
\hline H6: Service Quality $\rightarrow$ Negative Emotion & -0.320 & $-7.104^{* * *}$ & Yes \\
\hline H7: Positive Emotion $\rightarrow$ Customer Service Experience & 0.127 & $2.716^{* *}$ & Yes \\
\hline H8: Negative Emotion $\rightarrow$ Customer Service Experience & -0.084 & $-2.057^{*}$ & Yes \\
\hline H9: Food Quality $\rightarrow$ Customer Service Experience & 0.165 & $3.513^{* * *}$ & Yes \\
\hline H10: Restaurant Atmospherics $\rightarrow$ Customer Service Experience & 0.550 & $10.417^{* * *}$ & Yes \\
\hline H11: Service Quality $\rightarrow$ Customer Service Experience & 0.019 & $2.386^{*}$ & Yes \\
\hline H12: Perceived Quality $\rightarrow$ Positive Emotion & 0.761 & $10.586^{* * *}$ & Yes \\
\hline H13: Perceived Quality $\rightarrow$ Negative Emotion & -0.439 & $-7.695^{* * *}$ & Yes \\
\hline H14: Perceived Quality $\rightarrow$ Customer Service Experience & 1.311 & $5.988^{* * *}$ & Yes \\
\hline
\end{tabular}

Note: $\mathrm{ns}=$ not significant

${ }^{*} p<0.05 ; * * p<0.01 ; * * * p<0.001$. 


\section{Testing for indirect effects}

Mediation analysis was performed on the better competing model $\left(\mathrm{CM}_{1}\right)$ to assess the mediation effects of positive emotions and negative emotions on the relationship between the various cognitive factors and CSE. We employed a bootstrapping technique ( $n=5,000$ bootstrap resamples) to estimate the sampling distribution of the indirect effects. Furthermore, we expected that positive emotions (PE) would mediate the relationship between FQ $\rightarrow \mathrm{CSE}, \mathrm{RAT} \rightarrow \mathrm{CSE}$ and $\mathrm{SQ} \rightarrow \mathrm{CSE}\left(\mathrm{H}_{15 \mathrm{a}, \mathrm{b}, \mathrm{c}}\right)$. As depicted in Table 6, the findings revealed that FQ, RAT and SQ influence $\mathrm{CSE}$ indirectly through $\mathrm{PE}\left(\beta_{\mathrm{FQ}} \rightarrow \mathrm{PE} \rightarrow \mathrm{CSE}=0.025, p<0.05\right.$, boots $\mathrm{CI}=0.154-0.736 ; \beta_{\mathrm{RAT} \rightarrow \mathrm{PE} \rightarrow \mathrm{CSE}}$ $=0.018, p<0.05$, boots $\mathrm{CI}=0.006-0.038 ; \beta_{\mathrm{SQ} \rightarrow \mathrm{PE} \rightarrow \mathrm{CSE}}=0.029, p<0.05$, boots $\mathrm{CI}=0.007-$ 0.054). Accordingly, $\mathrm{H}_{15}$ was supported. The results also indicated that negative emotions (NE) mediated the effects of both FQ $\left(\beta_{\mathrm{FQ} \rightarrow \mathrm{NE} \rightarrow \mathrm{CSE}}=-0.011, p<0.05\right.$, boots $\mathrm{CI}=-0.026$ to -0.002$)$ and SQ $\left(\beta_{\mathrm{SQ} \rightarrow \mathrm{NE} \rightarrow \mathrm{CSE}}=-0.018, p<0.05\right.$, boots $\mathrm{CI}=-0.035$ to -0.004$)$ on CSE. To the contrary, the

effect of RAT on CSE via NE was statistically insignificant. Thus, there is partial support for $\mathrm{H}_{16}$. The results of the indirect effects are presented in Table 6.

Table 6 - Results of the indirect effects

\begin{tabular}{|c|c|c|c|}
\hline Indirect effects & $\beta$ & Boo & $\mathrm{S} \mathrm{CI}^{1}$ \\
\hline H15a: Food Quality $\rightarrow$ Positive Emotion $\rightarrow$ Customer Service Experience & $.025^{*}$ & .154 & .736 \\
\hline H15b: Restaurant Atmosphere $\rightarrow$ Positive Emotion $\rightarrow$ Customer Service Experience & $.018^{*}$ & .006 & .038 \\
\hline H15c: Service Quality $\rightarrow$ Positive Emotion $\rightarrow$ Customer Service Experience & $.029^{*}$ & .007 & .054 \\
\hline H16a: Food Quality $\rightarrow$ Negative Emotion $\rightarrow$ Customer Service Experience & $-.011^{*}$ & -.026 & -.002 \\
\hline H16b: Restaurant Atmosphere $\rightarrow$ Negative Emotion $\rightarrow$ Customer Service Experience & $-.001^{\mathrm{ns}}$ & -.013 & .004 \\
\hline H16،: Service Quality $\rightarrow$ Negative Emotion $\rightarrow$ Customer Service Experience & $-.018^{*}$ & -.035 & -.004 \\
\hline
\end{tabular}

\section{Discussion and implications}

\section{Theoretical implications}

The study confirms several existing relationships in the literature in line with the cognitive-affectbehavior response system (Holbrook \& Hirschman, 1982). In ethnic restaurants, similar to other types of restaurants, cognitive factors such as FQ, SQ and RAT arouse positive emotions in customers, as suggested by $\mathrm{H}_{1}, \mathrm{H}_{3}$ and $\mathrm{H}_{5}$. These results align with the findings of some previous 
studies suggesting that positive emotions are outcomes of evaluations of FQ and RAT (Prayag et al., 2015; Tsaur et al., 2015) but contradict others which showed that FQ (Chen et al., 2015; Jang \& Namkung, 2009) and RAT (Peng et al., 2017) do not arouse positive emotions. Nonetheless, the study confirms that FQ is an important attribute that customers evaluate in assessing the restaurant experience (Ha \& Jang, 2010; Jang \& Namkung, 2009; Ryu, Lee, \& Gon Kim, 2012). Similar to casual dining and luxury restaurants, in ethnic restaurants food temperature, freshness, authenticity, menu variety and food presentation are some of the attributes that customers evaluate in assessing FQ (Chen et al., 2015; Liu \& Jang, 2009a; Prayag et al., 2015).

In a similar way, the findings confirm some studies that suggest an important antecedent of positive emotions is SQ (Jang \& Namkung, 2009; Peng et al., 2017; Tsaur et al., 2015). The results of $\mathrm{H}_{2}$ and $\mathrm{H}_{6}$ confirm previous studies suggesting that FQ and SQ can arouse negative emotions (Peng et al., 2017) but contradict others that could not establish a significant relationship between SQ and negative emotions (Jang \& Namkung, 2009). SQ remains nevertheless a strong determinant of positive emotions and has some influence on customer evaluation of the service experience. During the service encounter, the interactions between staff and customers are evaluated on dimensions such as friendliness, helpfulness, competency, and personalization as suggested in previous studies (Jang \& Namkung, 2009; Prayag et al., 2017; Tsaur et al., 2015). In addition, perceived safety of the restaurant location is also an important attribute that customers consider in their evaluation of the restaurant experience.

$\mathrm{H}_{4}$ confirms that RAT has no influence on negative emotions as suggested in previous studies (Chen et al., 2015; Jang \& Namkung, 2009). The supporting and contradictory results from this study on the relationship between cognitive factors and emotions can be enlightened by contextual differences and the fact that previous studies have not necessarily investigated these relationships in ethnic restaurants. Ethnic restaurants can generate different experiences compared to other types of restaurants through their food, service and atmospherics (Ha \& Jang, 2010). Despite the contradictory results on the influence of RAT on emotions across different studies (Chen et al., 2015; Peng et al., 2017; Prayag et al., 2015), when customers enter the restaurant, they gain an impression of its quality by experiencing the ambience, noise, décor, cleanliness and authenticity of the restaurant (Jang \& Namkung, 2009; Prayag et al., 2015; Ryu \& Han, 2010; Ryu et al., 2012). 
The affective responses elicited from cognitive factors have an influence on behavior (Holbrook \& Hirschman, 1982). As shown in this study, both positive and negative emotions can predict CSE. The support for $\mathrm{H}_{7}$ and $\mathrm{H}_{8}$ extends previous studies (Jang \& Namkung, 2009; Peng \& Cheng, 2015; Prayag et al., 2015; Tsaur et al., 2015) by showing that CSE is an important postconsumption behavior beyond satisfaction, behavioral intentions and loyalty. In fact, the direct influence of FQ, RAT and SQ on CSE $\left(\mathrm{H}_{9}, \mathrm{H}_{10}\right.$, and $\left.\mathrm{H}_{11}\right)$, extends the services marketing literature by providing empirical evidence of these relationships in ethnic restaurants compared to previous studies (Jüttner et al., 2013; Walter et al., 2010) that have employed mainly qualitative techniques. The mediating effects identified $\left(\mathrm{H}_{15}\right.$ and $\left.\mathrm{H}_{16}\right)$ support the cognitive-affective-behavior response system by showing that affective responses (positive and negative emotions) partially or fully mediate the relationships between FQ, RAT, SQ and CSE. This finding aligns with previous studies (Jang \& Namkung, 2009; Peng \& Chen, 2015; Peng et al., 2017; Prayag et al., 2015) suggesting the influence of cognitive factors on post-consumption behaviors via emotions. Yet these studies do not evaluate CSE as an outcome of consumption.

Despite previous studies suggesting that FQ, RAT, and SQ represent perceive quality (Ha \& Jang, 2012; Jang \& Namkung, 2009; Prayag et al., 2015), this approach had not yet been modelled in existing studies. Given the support found for the direct influence of PQ on positive emotions, negative emotions and $\mathrm{CSE}\left(\mathrm{H}_{12}, \mathrm{H}_{13}\right.$ and $\left.\mathrm{H}_{14}\right)$, these results suggest that PQ is a relevant second-order construct in modelling the relationship between cognitive and affective responses in restaurant settings. Consequently, this is one of the most significant contributions of this study. However, it should be noted that the competing model $\mathrm{CM}_{1}$ was by far the best fit for this data, highlighting the importance of testing alternative models within hospitality studies as suggested by others (Nunkoo et al., 2013).

\section{Practical implications}

Considering that PQ is a pivotal aspect of the restaurant (Jang \& Namkung, 2009; Prayag et al., 2015) experience, our results can benefit practitioners and restaurant managers. The results offer a better understanding of how SQ, RAT and FQ can elicit positive and negative emotions as well as how these factors can influence customer evaluations of the service experience (CSE). First and foremost, this study found that within the ethnic restaurant context, RAT has an important influence in arousing positive emotions leading to a positive consumer service experience. Therefore, 
restaurant managers should use service design principles to configure RAT and orchestrate service delivery. Service design principles emphasize touchpoints (Jüttner et al., 2013) and this study emphasizes the significance of three touch points (FQ, SQ and RAT).

Restaurant managers in Brazilian restaurants in the UK should set and manage quality standards related to both service and food to manage guest experiences. Specifically standards with respect to FQ, SQ and the integration of Brazilian themed restaurant atmospherics can induce positive emotions. To improve SQ, for example, emotional labor training for service employees would be effective in managing interactions between customers and guests in such a way that these interactions are perceived as of high quality. Similarly, restaurant managers should take effective measures to maintain high standards of FQ so that the authenticity of Brazilian cuisine is maintained. In this way, customer expectations can be met or exceeded, thus arousing positive emotions.

Furthermore, our findings also highlight not only outcomes of positive and negative emotions, that is CSE, but also the process through which FQ, SQ and RAT directly and indirectly influences CSE. As suggested in previous studies (Walter et al., 2010), understanding this process allows restaurant managers to think of service experiences holistically and coordinate as well as fine-tune both front-stage and back-stage service delivery. The mediating effects of both positive and negative emotions on the relationship between PQ and CSE suggest that emotional experiences are strong drivers of post-consumption behaviors and can be aroused by authentic Brazilian décor, ambience, food, music, employee uniforms, and friendliness of staff, among others.

Related to the above, the findings suggest that Brazilian restaurants in the UK should not focus only on food tasting good but also authenticity of the food, proportion served to customers, how the food is presented, freshness of the food, and availability of healthy alternatives on the menu. A holistic view of how food is prepared and served can contribute to enhancing perceptions of high food quality. Beyond the friendliness and helpfulness, staff must be trained in understanding Brazilian culture and cuisine. Staff must show good knowledge of the menu and display behaviors that create perceptions of reliability in the service delivered. Managing the timeline between customer order and delivery can contribute to enhance perceived competency and reliability of staff. Restaurant atmospherics such as music, décor, scents and aromas, and 
cleanliness must be used strategically to induce positive emotions and enhance the perceived overall customer experience.

\section{Limitations and avenues for future research}

Despite the contributions of this study to the hospitality and services marketing literatures, it is not without limitations. First, the study focuses on three high end ethnic Brazilian restaurants in UK and the sample is not representative of all such restaurants. However, no studies have yet assessed these types of restaurants in the UK. Second, since data were collected from those customers who did an online or phone call booking (around 80\%), walk in customers had no chance to participate in this study. In this sense, the findings may not be generalized to all customers that dined in the three restaurants surveyed. Third, CSE is a multi-dimensional construct (Klaus \& Maklan, 2012). In this study we have modelled this construct as an overall evaluation of the quality of CSE. It would be worthwhile for further researchers to evaluate the effect of FQ, SQ, RAT on CSE using all sub-dimensions of CSE. Fourth, the study adheres to the research strand conceptualizing CSE as an outcome of an experience (Lemke et al., 2011). There is also the view that CSE is a process rather than an outcome (Klaus \& Maklan, 2012) and therefore future studies should evaluate this competing view. Finally, measuring emotions retrospectively and using the valence approach have been the subject of much criticism in the literature (Prayag et al., 2017). It would be valuable for further studies to investigate the relationships between the cognitive factors (FQ, RAT and SQ) and discrete emotions (e.g., joy, excitement, and guilt).

\section{References}

Ali, F., Amin, M., \& Cobanoglu, C. (2015). An Integrated Model of Service Experience, Emotions, Satisfaction, and Price Acceptance: An Empirical Analysis in the Chinese Hospitality Industry. Journal of Hospitality Marketing \& Management, 25(4), 449-475.

Akaike, H. (1987). Factor analysis and AIC. Psychometrika, 52(3), 317-332.

Anderson, J. C., \& Gerbing, D. W. (1988). Structural equation modeling in practice: A review and recommended two-step approach. Psychological Bulletin, 103(3), 411-423. 
Browne, M. W., \& Cudeck, R. (1989). Single Sample Cross-Validation Indices for Covariance Structures. Multivariate Behavioral Research, 24(4), 445-455.

Chen, A., Peng, N., \& Hung, K. P. (2015). The effects of luxury restaurant environments on diners' emotions and loyalty: incorporating diner expectations into an extended Mehrabian-Russell model. International Journal of Contemporary Hospitality Management, 27(2), 236-260.

Crosby, P.B. (1979). Quality Is Free: The Art of Making Quality Certain. New York: New American Library.

DiPietro, R. B., Khan, M. A., \& Bufquin, D. (2017). Customer perceptions of "McService": Relationship with return intention. Journal of Foodservice Business Research, 20(3), 286303.

Dweck, C. S., \& Leggett, E. L. (1988). A social-cognitive approach to motivation and personality. Psychological Review, 95(2), 256-273.

Edvardsson, B. (2005). Service quality: beyond cognitive assessment. Managing Service Quality: An International Journal, 15(2), 127-131.

Edvardsson, B., Enquist, B., \& Johnston, R. (2010). Design dimensions of experience rooms for service test drives: case studies in several service contexts. Managing Service Quality: An International Journal, 20(4), 312-327.

Fornell, C., \& Larcker, D. F. (1981). Evaluating structural equation models with unobservable variables and measurement error. Journal of marketing research, 18(1), 39-50.

Gentile, C., Spiller, N., \& Noci, G. (2007). How to sustain the customer experience:: An overview of experience components that co-create value with the customer. European Management Journal, 25(5), 395-410.

Gustafsson, I. B., Öström, Å., Johansson, J., \& Mossberg, L. (2006). The Five Aspects Meal Model: a tool for developing meal services in restaurants. Journal of Foodservice, 17(2), 84-93.

Ha, J., \& Jang, S. (2010). Effects of service quality and food quality: The moderating role of atmospherics in an ethnic restaurant segment. International Journal of Hospitality Management, 29(3), 520-529.

Ha, J., \& Jang, S. (2012). The effects of dining atmospherics on behavioral intentions through quality perception. Journal of Services Marketing, 26(3), 204-215.

Hair, J. F., Black, W. C., Babin, B. J., \& Anderson, R. E. (2014). Multivariate Data Analysis: Pearson New International Edition (7 ed.): Pearson Education, Limited.

Han, H., \& Hyun, S. S. (2017). Impact of hotel-restaurant image and quality of physicalenvironment, service, and food on satisfaction and intention. International Journal of Hospitality Management, 63, 82-92. 
Havlena, W. J., \& Holbrook, M. B. (1986). The varieties of consumption experience: comparing two typologies of emotion in consumer behavior. Journal of Consumer Research, 13(3), 394-404.

Helkkula, A. (2011). Characterising the concept of service experience. Journal of Service Management, 22(3), 367-389.

Holbrook, M. B., \& Hirschman, E. C. (1982). The experiential aspects of consumption: Consumer fantasies, feelings, and fun. Journal of Consumer Research, 9(2), 132-140.

Hu, L. t., \& Bentler, P. M. (1999). Cutoff criteria for fit indexes in covariance structure analysis: Conventional criteria versus new alternatives. Structural Equation Modeling: A Multidisciplinary Journal, 6(1), 1-55.

Iglesias, M. P, \& Guillén, M. J. Y. (2004). Perceived quality and price: their impact on the satisfaction of restaurant customers. International Journal of Contemporary Hospitality Management, 16(6), 373-379.

Izard, C.E. (1977). Human Emotions. New York: Plenum.

Jang, S., \& Namkung, Y. (2009). Perceived quality, emotions, and behavioral intentions: Application of an extended Mehrabian-Russell model to restaurants. Journal of Business Research, 62(4), 451-460.

Jüttner, U., Schaffner, D., Windler, K., \& Maklan, S. (2013). Customer service experiences: Developing and applying a sequentialincident laddering technique. European Journal of Marketing, 47(5/6), 738-769.

Kincaid, C., Baloglu, S., Mao, Z., \& Busser, J. (2010). What really brings them back? The impact of tangible quality on affect and intention for casual dining restaurant patrons. International Journal of Contemporary Hospitality Management, 22(2), 209-220.

King, S. C., Meiselman, H. L., \& Carr, B. T. (2010). Measuring emotions associated with foods in consumer testing. Food Quality and Preference, 21(8), 1114-1116.

Klaus, P., \& Maklan, S. (2012). EXQ: a multiple-item scale for assessing service experience. Journal of Service Management, 23(1), 5-33.

Kline, R., B. (2016). Principles and Practice of Structural Equation Modeling (4ht ed.). New York: The Guilford Press.

Lazarus, R. S. (1991). Cognition and motivation in emotion. American Psychologist, 46(4), 352.

Laros, F. J., \& Steenkamp, J. B. E. (2005). Emotions in consumer behavior: a hierarchical approach. Journal of business Research, 58(10), 1437-1445. 
Lemke, F., Clark, M., \& Wilson, H. (2011). Customer experience quality: an exploration in business and consumer contexts using repertory grid technique. Journal of the Academy of Marketing Science, 39(6), 846-869.

Lemon, K. N., \& Verhoef, P. C. (2016). Understanding customer experience throughout the customer journey. Journal of Marketing, 80(6), 69-96.

Lin, I. Y., \& Mattila, A. S. (2010). Restaurant servicescape, service encounter, and perceived congruency on customers' emotions and satisfaction. Journal of Hospitality Marketing \& Management, 19(8), 819-841.

Liu, Y., \& Jang, S. S. (2009a). The effects of dining atmospherics: An extended Mehrabian-Russell model. International Journal of Hospitality Management, 28(4), 494-503.

Liu, Y., \& Jang, S. (2009b). Perceptions of Chinese restaurants in the U.S.: What affects customer satisfaction and behavioral intentions? International Journal of Hospitality Management, 28(3), 338-348.

MacCallum, R. C., \& Austin, J. T. (2000). Applications of Structural Equation Modeling in Psychological Research. Annual Review of Psychology, 51(1), 201-226.

MacKenzie, S. B., Podsakoff, P. M., \& Jarvis, C. B. (2005). The problem of measurement model misspecification in behavioral and organizational research and some recommended solutions. Journal of Applied Psychology, 90(4), 710-730.

Miao, L., \& Mattila, A. S. (2013). The impact of other customers on customer experiences: a psychological distance perspective. Journal of Hospitality \& Tourism Research, 37(1), 7799.

Namkung, Y., \& Jang, S. (2007). Does Food Quality Really Matter in Restaurants? Its Impact On Customer Satisfaction and Behavioral Intentions. Journal of Hospitality \&amp; Tourism Research, 31(3), 387-409.

Nunkoo, R., Ramkissoon, H., \& Gursoy, D. (2013). Use of structural equation modeling in tourism research: past, present, and future. Journal of Travel Research, 52(6), 759-771.

Olson, J. C., \& Jacoby, J. (1972). Cue utilization in the quality perception process. ACR Special Volumes. Proceedings of the $3^{\text {rd }}$ Annual Conference of ACR, Ann Arbor, MI (pp.167-179).

Olsson, L. E., Friman, M., Pareigis, J., \& Edvardsson, B. (2012). Measuring service experience: Applying the satisfaction with travel scale in public transport. Journal of Retailing and Consumer Services, 19(4), 413-418.

Pachankis, J. E. (2007). The psychological implications of concealing a stigma: a cognitiveaffective-behavioral model. Psychological Bulletin, 133(2), 328-345.

Palmer, A. (2010). Customer experience management: a critical review of an emerging idea. Journal of Services marketing, 24(3), 196-208. 
Parasuraman, A., Zeithaml, V. A., \& Berry, L. L. (1988). Servqual: A multiple-item scale for measuring consumer perceptions of service quality. Journal of Retailing, 64(1), 12-40.

Peng, N., \& Chen, A. H. (2015). Diners' loyalty toward luxury restaurants: the moderating role of product knowledge. Marketing Intelligence \& Planning, 33(2), 179-196.

Peng, N., Chen, A., \& Hung, K. P. (2017). The effects of teppanyaki restaurant stimuli on diners' emotions and loyalty. International Journal of Hospitality Management, 60, 1-12.

Phillips, D. M., \& Baumgartner, H. (2002). The role of consumption emotions in the satisfaction response. Journal of Consumer Psychology, 12(3), 243-252.

Podsakoff, P. M., MacKenzie, S. B., Lee, J.-Y., \& Podsakoff, N. P. (2003). Common method biases in behavioral research: a critical review of the literature and recommended remedies. Journal of Applied Psychology, 88(5), 879-903.

Prayag, G., Khoo-Lattimore, C., \& Sitruk, J. (2015). Casual Dining on the French Riviera: Examining the Relationship Between Visitors' Perceived Quality, Positive Emotions, and Behavioral Intentions. Journal of Hospitality Marketing \& Management, 24(1), 24-46.

Prayag, G., Hosany, S., Muskat, B., \& Del Chiappa, G. (2017). Understanding the relationships between tourists' emotional experiences, perceived overall image, satisfaction, and intention to recommend. Journal of Travel Research, 56(1), 41-54.

Rahman, I., Park, J., \& Chi, C. G. Q. (2015). Consequences of “greenwashing” Consumers' reactions to hotels' green initiatives. International Journal of Contemporary Hospitality Management, 27(6), 1054-1081.

Ryu, K., \& Han, H. (2010). Influence of the quality of food, service, and physical environment on customer satisfaction and behavioral intention in quick-casual restaurants: Moderating role of perceived price. Journal of Hospitality \& Tourism Research, 34(3), 310-329.

Ryu, K., \& Jang, S. S. (2007). The effect of environmental perceptions on behavioral intentions through emotions: The case of upscale restaurants. Journal of Hospitality \& Tourism Research, 31(1), 56-72.

Ryu, K., Lee, H. R., \& Gon Kim, W. (2012). The influence of the quality of the physical environment, food, and service on restaurant image, customer perceived value, customer satisfaction, and behavioral intentions. International Journal of Contemporary Hospitality Management, 24(2), 200-223.

Schmitt, B., Joško-Brakus, J., \& Zarantonello, L. (2015). From experiential psychology to consumer experience. Journal of Consumer Psychology, 25(1), 166-171.

Sulek, J. M., \& Hensley, R. L. (2004). The relative importance of food, atmosphere, and fairness of wait: The case of a full-service restaurant. Cornell Hotel and Restaurant Administration Quarterly, 45(3), 235-247. 
Tabachnick, B., G., \& Fidell, L., S. (2013). Using Multivariate Statistics (6th ed.). Boston: Pearson.

Tsaur, S.-H., Luoh, H.-F., \& Syue, S.-S. (2015). Positive emotions and behavioral intentions of customers in full-service restaurants: Does aesthetic labor matter? International Journal of Hospitality Management, 51(Supplement C), 115-126.

Vargo, S. L., \& Lusch, R. F. (2008). Service-dominant logic: continuing the evolution. Journal of the Academy of Marketing Science, 36(1), 1-10.

Walter, U., \& Edvardsson, B. (2012). The physical environment as a driver of customers' service experiences at restaurants. International Journal of Quality and Service Sciences, 4(2), 104-119.

Walter, U., Edvardsson, B., \& Öström, Å. (2010). Drivers of customers' service experiences: a study in the restaurant industry. Managing Service Quality: An International Journal, 20(3), 236-258.

Watson, D., Clark, L. A., \& Tellegen, A. (1988). Development and validation of brief measures of positive and negative affect: The PANAS scales. Journal of Personality and Social Psychology, 54(6), 1063-1070.

West, S. G., Finch, J. F., \& Curran, P. J. (1995). Structural equation models with nonnormal variables: Problems and remedies. In R. H. Hoyle (Ed.), Structural equation modeling: Concepts, issues, and applications. (pp. 56-75). Thousand Oaks, CA, US: Sage Publications, Inc.

Zeithaml, V. A., Berry, L. L., \& Parasuraman, A. (1988). Communication and control processes in the delivery of service quality.The Journal of Marketing, 52(2), 35-48. 